\title{
La conciencia de la diferencia étnica: identidad y distancia cultural en el discurso del profesorado
}

\section{Eduardo Terrén}

Universidade da Coruña

Departamento de Socioloxía e Ciencia Política e da Administración

Campus de Elviña. 15071 A Coruña

soso@udc.es

\section{Resumen}

El trabajo que aquí se presenta se estructura en tres partes. En la primera se ofrece el marco teórico desde el que se aborda el problema general analizado: la representación de la diferencia en el marco de las relaciones interétnicas. En la segunda se subraya la importancia del estudio de este problema para el desarrollo de la educación intercultural y, más concretamente, para el mejor conocimiento de la forma en que uno de sus agentes fundamentales, el profesorado, construye esa diferencia. En la tercera se ofrece una interpretación de los resultados parciales de una investigación empírica. Se concluye que, al menos en este caso, la percepción de la diferencia étnica está ligada a la construcción de la propia identidad y a procesos de categorización jerárquica, que se explican por la capacidad del grupo dominante para clasificar y situar adscriptivamente a los otros en una escala de distancia cultural percibida.

Palabras clave: identidad, diferencia étnica, educación intercultural.

\section{Abstract. The consciousness of ethnic difference: identity and cultural distance in teacher's discourse}

This paper is divided in three parts. First of all, it explores the theoretical frame needed for the analysis of the main question: the representation of difference within ethnic relations. The second part stresses the importance of this question for the development of intercultural education and particularly for a more precise account of the way in which teachers build that difference. The third part reports the findings of a study of teachers discourse on their gypsies and second-generation immigrants pupils. It is suggested that their perception of ethnic difference is tied to the building of their own identity and to processes of hierarchical categorization which have to be understood in relation with the power of the dominant group to classify the others along a scale of cultural distance.

Key words: identity, ethnic difference, intercultural education.

\section{Sumario}

1. Identidad, poder y discurso en el análisis de las relaciones étnicas

2. El poder de la exclusión y la educación intercultural
3. La señalización de la diferencia étnica en el discurso del profesorado

Bibliografía 


\section{Identidad, poder y discurso en el análisis de las relaciones étnicas}

¿Cómo piensan los miembros de una etnia mayoritaria acerca de los que no pertenecen a ella? El estudio sociológico de los mecanismos de representación de la diferencia en los que se producen las relaciones étnicas debe construir su fundamentación teórica en los campos de la sociología del poder y la sociología del conocimiento. Sólo así puede entenderse cómo la representación de las diferencias se relaciona con los discursos de exclusión e inclusión que forman parte de la estructura social y con nuestra percepción de las distancias sociales que median entre nosotros y quienes — como señaló Simmel (1986) — sentimos a un mismo tiempo cercanos y lejanos.

Una relación étnica -0 , más propiamente, interétnica — comprende como rasgo esencial una caracterización diferencial de los sujetos implicados en ella en función de su etnicidad, tanto si ésta es atribuida como si es resultado de una autoadscripción. El problema estriba en que la propia noción de etnicidad es tremendamente escurridiza y poco apropiada como para servir de marco de referencia a una investigación, si no se le somete a una rigurosa formalización conceptual ${ }^{1}$. Hace ya mucho tiempo que el único de los padres de la sociología que se ocupó del estudio de las comunidades étnicas advirtió sobre ello (Weber, 1979: 324).

En un curioso paralelismo con el giro boasiano hacia la antropología cultural y su énfasis en las creencias y las costumbres, y sin que existiesen precedentes de lo mismo en los clásicos de la sociología, Weber (1979: 313-327) abordó el estudio de las comunidades étnicas desde el punto de vista de la comunidad "subjetivamente sentida» y de un específico "sentimiento étnico» ligado a la percepción del "honor social»: "llamaremos "grupos étnicos" - decía Weber- a aquellos grupos humanos que fundándose en la semejanza del hábito exterior y de las costumbres, o de ambos a la vez, o en recuerdos de colonización y migración, abrigan una creencia subjetiva en una procedencia común» (1979: 319). Así, distanciándose explícitamente de las versiones más biologicistas de la raza, Weber hace descansar el análisis de la etnicidad en "la diferencia sentida», tanto si ésta procede de una disposición como de si lo hace de una tradición. Ésta es la visión de la conciencia de la diferencia que se pretende desarrollar en este trabajo.

La tradición de investigación en la que pretende enmarcarse nuestro trabajo entronca con el análisis de las relaciones étnicas o raciales puesta en marcha por la Escuela de Chicago hace ya ochenta años. Los sociólogos que flo-

1. Un primer esbozo de este tipo de reflexión fue abordado en Terrén (1996). La visión subyacente a las investigaciones allí comentadas podría resumirse en la definición ofrecida por Sandra Wallman (1979: 3), exponente de la orientación en la que se inscribe este trabajo: «etnicidad es el proceso por el que "su" diferencia es utilizada para reforzar el sentido de "nosotros" con vistas a objetivos de organización e identificación [...] la etnicidad sólo puede producirse en los límites del "nosotros", en contacto o confrontamiento o contraste con "ellos". A medida que cambia el sentido del "nosotros", varían también los límites entre "ellos" y "nosotros". No sólo los límites varían, sino también los criterios que los marcan». 
recieron en torno a esta escuela fueron los primeros en superar las explicaciones de fenómenos como el racismo o los prejuicios étnicos en términos de componentes supuestamente esenciales de las razas, e impulsaron su investigación en el marco del estudio de las relaciones, es decir, en el marco de los contactos concretos que se producen entre los portadores de atributos étnicos diversos ${ }^{2}$. Everett Hughes describió este marco precisamente como una ecología del contacto.

Es propio de este programa de investigación el trasladar el énfasis de la raza a la cultura y, frente a la disección de rasgos raciales más o menos innatos de cada grupo, propiciar el análisis de las interacciones y las situaciones de encuentro que se establecen entre los miembros de dichos grupos. El que quizá haya sido el más sobresaliente exponente de este enfoque, Robert Park, definió lo que debía entenderse por una relación étnica como una relación "entre pueblos con marcas distintivas de origen racial, particularmente cuando tales diferencias raciales penetran en la conciencia de los individuos y de los grupos así identificados, determinando de ese modo la concepción que cada individuo tiene tanto de sí mismo como de su estatus dentro de la comunidad» (1950: 181).

Interesa destacar en la definición de Park la importancia de la conciencia y los mecanismos de identificación, pues esto ayuda a comprender cómo el desplazamiento analítico hacia las situaciones de relación no supone, sino todo lo contrario, un abandono de la dimensión subjetiva de la relación. El análisis del conflicto étnico, efectivamente, no puede disociarse del de las relaciones concretas e históricamente modificables en que se produce, pero tampoco de la subjetividad con la que dichas relaciones son vividas por los sujetos implicados en la relación; esto es, de lo que clásicamente se ha venido denominando en sociología su «definición de la situación». El propio Park subrayó este punto al afirmar que lo que caracteriza a las relaciones étnicas no son solamente los atri-

2. Esta visión relacional de la etnicidad — sugerida también por la visión de Wallman anteriormente señalada - fue desarrollada más tarde por Herbert Blumer, un autor que sirvió de puente entre el núcleo clásico de la Escuela de Chicago y la corriente del interaccionismo simbólico de los sesenta, pero puede considerarse también afín a la teoría de las relaciones étnicas propuesta por esos mismos años en Europa por Barth, muy en la línea de la sociología interpretativa weberiana. La teoría de Barth acerca de la organización social de las diferencias culturales hace ese mismo hincapié en el principio de la autoadscripción o la adscripción por otros como motor de esa organización. La clave del planteamiento de Barth se refleja en el propio título de su trabajo clásico, que reproduce la idea de que las fronteras o límites de la etnicidad son divisorias imaginadas y en constante redefinición según la posición que los actores adopten o quieran adoptar en las diferentes situaciones de encuentro. Y, en definitiva, podríamos decir que ésta es la interpretación vigente hoy día en el ámbito interdisciplinario de los Cultural Studies. Es una interpretación que destaca por encima de otros los elementos afectivos y cognitivos de la etnicidad como construcción social, pero a la que se le ha objetado el haber descuidado en ocasiones el marco estructural de poder en el que se producen esas significaciones subjetivas. Como se verá, nuestra introducción del modelo «establecidos/marginales» desarrrollado por Elias pretende superar esta limitación. 
butos físicamente visibles, sino también - y sobre todo- los elementos que tienen que ver con la conciencia identitaria: «La conciencia de raza [...] debe considerarse un fenómeno del mismo orden que la conciencia de clase o de casta [...]; las relaciones raciales [...] no son tanto relaciones entre individuos de diferentes razas como entre individuos conscientes de esas diferencias" (1950: 181, cursiva mía). El trabajo aquí presentado puede leerse de hecho como un estudio de la manifestación de esta conciencia de la diferencia.

Pero, por otro lado, la importancia de la significación subjetiva de la etnicidad no debe hacer perder de vista el componente estructural en el que se produce esa significación. Dicho de otra forma, la producción de la diferencia y de la autoidentificación se produce siempre en el marco de una determinada configuración de relaciones de poder. Al fin y al cabo, como señaló Elias (1997: 46), «las llamadas "relaciones raciales" no son siempre más que un tipo particular de relaciones entre establecidos y marginales [établis-marginaux, established-outsiders]", es decir, se producen siempre en un marco determinado de relaciones de poder históricamente determinadas.

El modelo de representación «establecidos-marginados» nos sirve, pues, como "paradigma empírico» (Elias, 1997: 32) sobre el que desarrollar nuestra cuestión. Así, en nuestro análisis, la manifestación discursiva de la conciencia de la diferencia étnica es puesta en relación con la posición asimétrica de poder que ostentan quienes en este caso definen la situación de encuentro interétnico. Los procesos de inclusión y exclusión que se producen en las relaciones étnicas se configuran en una dinámica de conflicto cultural impulsada por sentimientos de gratificación o frustración que generan motivaciones tan diversas como la creencia en la superioridad del etnogrupo, la percepción de las gratificaciones de la sumisión y la asimilación o la voluntad de resistencia. Quienes intervienen en una relación étnica lo hacen desde posiciones diferenciadas de poder cultural y tienden a desarrollar mecanismos de representación y autoidentificación que definen su situación percibida y legitiman su actuación.

Como recuerda el propio Elias, toda metodología inspirada en una teoría que explique el diferencial de poder en términos exclusivamente de posesiones materiales y olvide la representación subjetiva de ese diferencial es necesariamente limitada. Un mecanismo psicosociológico tan fundamental en la configuración de la relación étnica como es, por ejemplo, el de la estigmatización quedaría, así, pobremente explicado si no comenzara por «examinar de cerca la idea que una persona se hace de la posición de su grupo entre los otros y, por tanto, de su propia posición dentro de ese grupo» (Elias, 1997: 38).

El examen de las autoposiciones culturales diferenciadas como elemento clave de la producción de la relación étnica nos ha obligado a buscar una perspectiva de análisis que potenciara la dimensión expresiva de las representaciones de la diferencia étnica y que, en consecuencia, concediera un lugar metodológico destacado al examen del discurso de los sujetos implicados en la relación que constituye nuestro objeto de estudio. Como señala Woodward (1997: 14) desarrollando la idea del «circuito de la cultura» de Stuart Hall: 
«los discursos y los sistemas de representación construyen lugares desde los que los individuos pueden situarse a sí mismos y hablar». Esta perspectiva prima una visión constructivista de la relación entre el lenguaje y el significado, como es habitual en el ámbito de los Cultural Studies. El lenguaje construye el significado, no simplemente «refleja» un referente exterior, sino que más bien, «representa» a ese referente y, en esa medida, nos representa a nosotros mismos respecto a él. Por eso, «el significado es lo que nos da un sentido de nuestra propia identidad, de quién somos y a quién pertenecemos, [y] por eso está relacionado con las cuestiones de cómo se utiliza la cultura para marcar y mantener la identidad y la diferencia entre grupos» (Hall, 1997: 3). El lenguaje no sólo refleja la estructura social, sino que también la construye.

Partimos, pues, del supuesto básico de que —en la línea desarrollada por el análisis crítico del discurso (Van Dijk, 1987, 1988; Riggins, 1997) — las estructuras del discurso reflejan estructuras de acción. Por discurso entendemos aquí un cuerpo sistemático e internamente consistente de representaciones con que el lenguaje representa una determinada práctica social desde un cierto punto de vista (Fairclough, 1995: 56, cit. en Riggins, 1997: 2, que concluye: «los discursos no reflejan fielmente la realidad como espejos [...] Más bien, son artefactos lingüísticos a través de los cuales se construye la propia realidad que se proponen reflejar»).

Así, pues, consideramos la representación discursiva de los otros como un aspecto central de la identificación que se establece a través de los mecanismos simbólicos de inclusión y exclusión que, según Elias, caracterizan a toda relación social configurada sobre el paradigma establecidos-marginados, como es el caso — desde luego- de la relación interétnica. Como veremos, también, en la medida en que esta relación es una relación de poder, los mecanismos de conocimiento que intervienen en ella envuelven procesos de categorización discursiva que se explican por la capacidad de cada grupo para clasificar y situar adscriptivamente a los otros en una escala de distancia cultural percibida $^{3}$.

El análisis de estos mecanismos de producción de la diferencia orienta el estudio más hacia las estrategias discursivas de los actores implicados en una relación interétnica que hacia un análisis más propiamente estructural del fenómeno ideológico del racismo. El problema fundamental con el que relaciona-

3. Éste es un enfoque característico de antropólogos sociales como Jenkins (1986), pero una fundamentación más cercana a la sociología del conocimiento puede encontrarse también en Schütz (1974), para quien el mundo social aparece siempre para el sujeto de conocimiento como estratificado en diferentes capas de significatividad. Nuestro intento de conectar el énfasis de Elias en las relaciones de poder con el conocimiento jerarquizado de la realidad social estriba en que el sujeto de conocimiento — según Schütz- «agrupa el mundo alrededor de él mismo (en tanto que centro) como un campo de dominación" y se interesa especialmente por el sector que está más dentro de su alcance, el más significativo, aquél que puede servirle para promover sus objetivos. Esta jerarquía de significatividad vendría a ser el fundamento epistemológico de los sistemas de señalización de la diferencia que manifiestan distancias culturales percibidas. 
mos esa producción de la diferencia es el problema de la identidad ${ }^{4}$. Bien entendido que se trata de una visión de la «identidad en proceso» (Weinreich, 1986), es decir, de una identidad que fluctúa discursivamente ante la percepción de la amenaza entre su afirmación y la adscripción de identidades étnicas diferenciadas a los subordinados.

El marco teórico de nuestra investigación, pues, nos enfrenta al análisis de la señalización de la diferencia étnica por parte de unos sujetos inscritos en una relación de poder, en la medida en que dicha señalización se hace presente a nuestro estudio a través de su discurso acerca de los otros y, en el fondo, acerca de sí mismos. Lo que se espera mostrar es cómo esa manifestación discursiva de la diferencia produce la relación étnica a través de un conocimiento evaluativo y graduado de la participación del otro en dicha relación y cómo, consecuentemente, ese conocimiento se traduce en un mapa de distancias culturales percibidas.

\section{El poder de la exclusión y la educación intercultural}

El escenario educativo ofrece un campo de pruebas fundamental para el estudio de la configuración de las relaciones étnicas. La investigación sobre la influencia del factor étnico en la escuela es algo reciente en nuestro país, pero la juventud de sus escasas dos décadas de historia contrasta con su extraordinaria intensidad (Murillo y otros, 1995; Grañeras, Gordo y cols., 1998; Grañeras, Gordo y Regil, 1999). No obstante, es probable que esta acelerada proliferación empírica no haya contado con la suficiente reflexión teórica, debido seguramente a que el área de la sociología de las relaciones étnicas no ha sido suficientemente atendida en nuestro país.

Partimos de la idea general de que la escuela es un lugar de encuentro, un escenario de conflicto en el que se han fraguado ( $\mathrm{y}$ también frustrado) de forma decisiva las expectativas de armonía e igualación social de quienes buscan incorporarse a una plena ciudadanía. Por eso constituye el campo social en el que más decisivamente se han librado - tanto desde el punto de vista simbólico como material - las batallas modernas en pro de la integración. El fracaso en la educación de la población inmigrante y las minorías étnicas puede suponer un punto de inflexión en el proceso de progresista de igualación conseguido por la coeducación y la comprehensividad (Clay y Cole, 1992; Puig, 1994; Santos Rego, 1994). Entender las razones que pueden conducir a este fracaso es el

4. La identidad es un problema filosófico, pero — como ha debido dejar claro la conexión descrita por Hall (1997) entre la afirmación de la identidad y la señalización de la diferencia- es un problema con profundas implicaciones sociológicas para una cuestión como la que aquí se estudia. Al tomar la identidad como problema básico subyacente a nuestro análisis de la construcción de la diferencia étnica, se hace buena una reflexión de Schütz (1974): el análisis de un problema sociológico concreto, suficientemente profundizado, conduce de manera inevitable a ciertas cuestiones filosóficas básicas que los sociólogos no pueden eludir. 
objetivo de las líneas de investigación en «educación intercultural», un campo que tiende a convertirse hoy día en una nueva dimensión de la educación cívica y en un escenario estelar de evaluación de la calidad de la democracia.

El principal reto teórico y político de la educación intercultural es el ofrecer un modelo que permita la defensa de la igualdad de oportunidades a través de la integración y, a un mismo tiempo, la defensa del derecho a la diferencia $\mathrm{y}$ al reconocimiento de las identidades culturales no mayoritarias. Pero este reto conlleva ciertos riesgos. Por ejemplo, el de que el reconocimiento de los particularismos étnicos pueda traducirse en un freno a la integración y en formas culturalistas de naturalizar la exclusión; o, más en relación con lo que aquí se trata, que el horizonte de la interculturalidad como meta política se disuelva en una prédica superficial de la tolerancia sin un examen exhaustivo de los procesos cognitivos y sociales a través de los que se produce la diferencia étnica.

Para controlar estos riesgos es para lo que es importante analizar cómo se producen y se reproducen esas diferencias en el escenario educativo, esto es, analizar en detalle lo que el Colectivo IOÉ (1999) denomina la «lógica diferenciadora» de los colectivos implicados en la configuración de las relaciones étnicas en la escuela.

En la configuración de estas relaciones intervienen diversos agentes. El estudio que aquí se ofrece analiza la producción de esa lógica diferenciadora en uno de ellos: el profesorado, un puntal decisivo del polo de los «establecidos» según el paradigma establecidos/marginales comentado en la sección anterior. Lo decisivo de su lugar en la configuración de las relaciones étnicas en la escuela deriva de su posición de poder a la hora de definir el sentido de dicha relación $^{5}$. Dicho de otra forma, su importancia radica en que si el proceso de asignación de atributos identitarios aquí ofrecido se prueba plausible, éste podría ser un serio obstáculo para el tipo de relación educativa que debería presuponer una pedagogía intercultural, porque supondría una especie de forma elemental de racismo (Wieviorka, 1992) capaz de generar exclusión. Supondría, cuando menos, un elemento de dificultad a tener en cuenta cuando se habla con excesiva simpleza de la posibilidad de integrar el reconocimiento de los particularismos y el trato igualitario.

Para obtener una justa medida de este poder de exclusión con el que cuentan los establecidos en el polo dominante de la relación, hemos de tener presente varias observaciones. En primer lugar, por ejemplo, Liégois (1998: 181) considera comprobado que en muchos casos la información de que disponen los enseñantes está muy sesgada por imágenes distorsionadas. «Las representaciones — afirma - a base de prejuicios y estereotipos se adhieren a esta información y también a la que el enseñante recibe la mayoría de las veces desde

5. Un estudio cercano sobre los mecanismos cognitivos diferenciadores en que se apoya la lógica conceptual del racismo latente en los futuros y futuras profesionales de la educación (García Castaño y otros, 1998) llama igualmente la atención acerca de la trascendencia que puede tener el deficiente conocimiento de la diversidad cultural que detectan en los sujetos estudiados. 
su infancia y que a menudo puede verse inducido a transmitir». Por eso, aunque intentan distanciarse personalmente de las representaciones comunes, la mayoría siguen manteniendo en su práctica actitudes etnocéntricas que afectan no sólo a la enseñanza de los gitanos — que es la minoría estudiada por Liegois-, sino también a la del alumnado étnicamente mayoritario. Pero, en segundo lugar, hemos de tener muy presente también que en el estudio de la experiencia educativa de inmigrantes y minorías étnicas estamos tratando normalmente con un alumnado cuyas desventajas sociales y culturales les confiere un alto grado de dependencia escolar (Pigford, 1992). Esta dependencia no sólo radica generalmente en el plano de sus carencias materiales (recursos didácticos, tiempo de trabajo extraescolar, etc.), sino también en el plano de las carencias simbólicas. En este último plano es donde el protagonismo del docente adquiere una dimensión especial. En concreto, como ha señalado Jordan (1988: 506 s.), «los estudiantes minoritarios identifican a los profesores como personas muy significativas, de forma que su autoconcepto está en gran medida determinado por cómo ellos sienten que sus maestros los perciben [...] estos niños son más dependientes del profesor y, también, más propensos que sus compañeros de la clase media a valorar la figura del maestro».

De ahí que tenga una tremenda importancia el estudio de la dinámica de las creencias y atribuciones que pueden transformar la percepción de la diferencia cultural por parte del profesorado en expectativas acerca del rendimiento del alumnado marcado por dicha diferencia.

Ciertamente, no hay evidencia suficiente para aceptar que los estereotipos y los prejuicios se traduzcan automáticamente en prácticas discriminatorias. No obstante, los efectos perniciosos de la pervivencia de estos prejuicios sobre la práctica educativa pueden admitirse al menos como posibilidad bien fundada a partir de las conocidas investigaciones sobre el «efecto Pigmalión» (Rosenthal y Jacobson, 1980; Rist, 1986): los prejuicios e imágenes estereotipadas que los sujetos de un polo de la relación étnica tengan sobre los del otro polo pueden convertirse, con mucha probabilidad, en profecías sobre el desempeño de éstos. La forma en que se produce esta conversión puede ser diversa (Good y Brophy, 1991: 122 s.): desde adaptaciones curriculares más o menos explícitas que empobrecen los contenidos y las tareas encargados a este tipo de alumnado hasta simplemente un menor interés por ellos en el número y, sobre todo, en la calidad de las interacciones de aula ${ }^{6}$.

El corpus de investigación sobre el origen de los prejuicios es tremendamente diverso en sus diagnósticos. Los factores sociales, culturales o psicológicos identificados como fuentes del mismo nos abren a un gran abanico de interpretaciones (Taguieff, 1980) respecto al que es muy difícil tomar partido, porque todas ellas se refieren a marcos teóricos muy heterogéneos que, más que oponerse, muchas veces se complementan. No obstante, aquí la cues-

6. Smith y Tomlinson (1989), por ejemplo, mostraron que el alumnado sometido a una constante interacción crítica tiende a registrar normalmente un bajo rendimiento educativo. 
tión no es adentrarnos en la discusión esencialista sobre la razón de ser del prejuicio étnico, sino analizar su manifestación discursiva - aparentemente paradójica - en el discurso de unos sujetos claramente motivados en su rechazo y con experiencia directa de contacto en una relación educativa interétnica. Los sujetos aquí analizados presentan de antemano dos características sobresalientes: denuncian las manifestaciones de racismo que encuentran en la comunidad educativa y en el resto de la sociedad en general, y tienen un conocimiento directo de las dificultades que entraña la educación de los niños y las niñas étnicamente diferenciados. Por estas dos razones, su representación de la otredad no puede explicarse simplemente en términos de prejuicio, sino que debe buscarse en la lógica misma de la representación diferenciadora que subyace a su juicio y en la conexión de dicha lógica con su experiencia profesional. Lo que interesa aquí analizar es, en definitiva, el sistema de representación de la diferencia étnica en el discurso del profesorado y ponerlo en relación con las percepciones sociales que afianzan su identidad profesional.

\section{La señalización de la diferencia étnica en el discurso del profesorado}

Lo que buscamos en este momento de la exposición es lo que, en los términos tradicionales de la sociología interaccionista, podría describirse como el «meterse en el proceso definitorio» de la situación interétnica. Nos centramos aquí en cómo los sujetos intervinientes —en este caso los docentes- se representan el objeto de estudio que aquí nos ocupa: la conciencia de la diferencia étnica en el ámbito escolar. Ya hemos explicado en las secciones anteriores porqué nos centramos en el discurso como medio de constitución de ese objeto y porqué los sujetos analizados ostentan un lugar preponderante en la configuración de las relaciones étnicas en el ámbito educativo. Hemos de ver ahora cómo se produce en la práctica esa constitución ${ }^{7}$.

En primer lugar, hemos de tener muy presente que dicha constitución se produce en el marco de una interacción solicitada (la entrevista), y que lo que se produce en ella es lo que Van Dijk (1987) denomina un «discurso delicado»: los informantes y las informantes han adquirido desde el principio conocimiento de los intereses de investigación que justifican dicha interacción y son

7. Los datos que se analizan a continuación proceden de la primera fase de una investigación sobre la experiencia educativa de los inmigrantes y las minorías étnicas en el área metropolitana de A Coruña, realizada entre 1998 y 1999. En ella se han analizado los datos suministrados por más de setenta documentos, principalmente entrevistas en profundidad, además de algunos grupos de discusión, tests sociométricos, dibujos e informes sobre observaciones realizadas durante el trabajo de campo. Los datos aquí expuestos se refieren a entrevistas y grupos de discusión llevados a cabo con profesores y profesoras que tienen o han tenido a su cargo alumnado gitano y/o extranjero. Una primera sistematización de estos datos se presentó en la VII Conferencia de Sociología de la Educación (Murcia, 1999). Las citas domumentales están marcadas por un registro que incluye: 1) el número del documento de procedencia; 2) su fuente (entrevista, grupo de discusión, etc.); 3) la posición instritucional del informante o la informante, y 4) su género. 
conscientes de transitar por un terreno difícil ${ }^{8}$. Es importante subrayar esta circunstancia, porque los datos obtenidos a partir de ella pueden muy bien ser sensibles a un cierto sesgo de imagen.

De hecho, es prácticamente una constante en todas las entrevistas realizadas el que, de forma normalmente repentina y sin ser nunca preguntados por ello, los sujetos entrevistados establezcan lo que denominaremos una cláusula de salvaguardia. El principal objetivo de esta cláusula parece ser salvaguardar la propia integridad moral del informante ante lo que pueda resultar de su discurso. Es como si los informantes quisieran garantizar que la imagen que van a proyectar va a ser aceptada, conscientes en su mayoría de que la interacción de la entrevista va a transcurrir por terrenos resbaladizos, donde a menudo se presentan zonas de ambigüedad y dilemas prácticos ante los que no es fácil tomar postura y sí, en cambio, criticar cualquier medida adoptada? ${ }^{9}$ Creo que es descabellado ver un paralelismo entre la actitud que subyace a la formulación de estas cláusulas de salvaguardia y las «respuestas aprendidas» que suelen viciar muchas de las encuestas de opinión que versan sobre la difusión del racismo (Izquierdo, 1996: 165).

Esta cláusula de salvaguardia se nos ha presentado bajo dos fórmulas: directa e indirecta (cuadro 1). La primera adopta diversas variantes, normalmente dentro de cláusulas adversativas, siempre reducibles a la fórmula «pero conste que no soy racista, ¿eh?» ${ }^{10}$. Dentro de la fórmula indirecta cabe distinguir dos versiones, según el recurso retórico utilizado. En la primera versión, la cláusula de salvaguardia aparece indirectamente a través de la distinción entre la teoría y la práctica, esto es, entre lo que sería deseable para uno y lo que no queda más remedio que resignarse a aceptar. Esta distinción se establece frecuentemente con referencia al contraste percibido entre los modelos abstractos («universitarios») de atención a la diversidad y la sordidez del bregar cotidiano con alumnado «simplemente difícil». En la segunda versión de manifestación indirecta, la cláusula de salvaguardia aparece a través de una racionalización del comportamiento racista de otros «otros» (normalmente, los padres de otros alumnos desaventajados pertenecientes a la mayoría étnica o usuarios de los servicios sociales pertenecientes también al mismo etnogrupo). Esta empatía con las razones del racismo ajeno alberga en buena medida una legitimación de

8. Van Dijk señala como manifestaciones discursivas de esa dificultad la proliferación de falsos comienzos, autoexplicaciones, frases entrecortadas, elusión de nombres de grupos étnicos sustituidos por pronombres, sonidos que indican duda o suspicacia («Ummm»).

9. Dicho sea de paso, éste no es un recurso discursivo exclusivo del profesorado. A lo largo de nuestra investigación hemos encontrado casos similares, por ejemplo, en padres: «No es por nada pero... ellos tienen sus cosas y su problemática... y con eso no quiero decir nada, ¿eh? yo no soy racista, pero oye...» (58EPV). Esta "maniobra discursiva» ha sido estudiada en estudiantes blancos norteamericanos como exponente de un nuevo race-talk (BonillaSilva y Forman, 2000).

10. Van Dijk (1987: 86, 91, 388) describe esta operación estratégica como una «negativa aparente» orientada a la preservación discursiva de una autoimagen positiva entremezclada con una presentación negativa del otro. 
Cuadro 1. Tipos de cláusula de salvaguardia.

\begin{tabular}{|c|c|c|}
\hline Cláusula & Fórmula & Ejemplo \\
\hline \multirow[t]{3}{*}{1} & Directa & «No es que yo sea racista, entiéndeme bien» (18ETV) \\
\hline & & $\begin{array}{l}\text { «Conste que para mí son todos iguales, ¿eh?» } \\
(35 \mathrm{EPM})\end{array}$ \\
\hline & & «Yo quiero ser liberal, pero...» (5EDM) \\
\hline \multirow[t]{2}{*}{2} & Indirecta & $\begin{array}{l}\text { "Una cosa es la teoría y otra la práctica, ¿sabes?» } \\
\text { (47EPV) }\end{array}$ \\
\hline & & $\begin{array}{l}\text { «Todo eso está muy bien, y ojalá fuera así, } \\
\text { pero en el día a día...» (45GDPM) }\end{array}$ \\
\hline 3 & Indirecta & $\begin{array}{l}\text { "Claro, luego hay racismo porque muchos padres se } \\
\text { quejan de que los gitanos reciben más ayuda... y, oye, } \\
\text { hay mucha gente necesitada» ( } 53 \text { PsM) }\end{array}$ \\
\hline
\end{tabular}

actitudes que pueden considerarse como un efecto perverso de medidas redistribuidoras (becas, ayudas de comedor, apoyo escolar) que termina por generar injusticias de reconocimiento.

La teorización sobre la presencia de esta cláusula en el discurso de los docentes debe realizarse en los términos de su funcionalidad en el contexto de la interacción en la que son utilizadas para asentar el autoestereotipo. Dicha funcionalidad podría explicarse seguramente con ayuda de la idea de la «lealtad dramatúrgica» buscada por los sujetos en su interacción (Goffman, 1987). Tal y como son formuladas, puede afirmarse que la utilización de dichas cláusulas obedece a un intento de controlar a la audiencia (al entrevistador en este caso) para asegurar que la imagen producida en el discurso coincida con la imagen que se supone como esperada por parte de dicha audiencia. Más concretamente, el tipo de mecanismo de control discursivo operante en este caso sería el de la «implicación», por la que el entrevistado hace por situarse en el mismo lado del entrevistador dando por sentada su ideología antiracista y haciendo gala de conocer sobradamente los atributos típicos (el equipo expresivo estándar — diría Goffman—) del profesor multiculturalista. Se asegura, así, la proyección de la imagen correspondiente a la identidad de rol esperada.

La identidad de rol esperada es un aspecto de la identidad social que se entremezcla con la identidad personal y/o profesional. El sujeto negocia su presencia en la interacción solicitada acentuando dicha identidad en determinados momentos del discurso, muy probablemente en función de la necesidad de reforzar una autoestereotipia ligada a una especial valoración del rol y a un sentimiento de eficacia en su desempeño ${ }^{11}$ : «Somos los más sensibilizados

11. Puede que en un tipo de profesorado tan directamente enfrentado a la realidad vivida del fracaso escolar la necesidad de satisfacción profesional sea especialmente relevante en la gestión de su identidad profesional. Como ha afirmado Jordán (1995: 60), «la primera actitud general que se presenta como crucial para trabajar con niños minoritarios es la de un sentimiento de eficacia en la mente del propio profesor». 
[...] porque hacemos del tener que sacar los niños adelante o no un problema gordo» (45GDPsV). Ha sido curioso observar, por ejemplo, cómo las cláusulas de salvaguardia tienden a ser menos utilizadas por aquellos sujetos que introducen en su discurso auténticas «narraciones de salvación» educativa, generalmente muy ricas en elementos descriptivos que subrayan la dureza de la empresa. Una maestra, por ejemplo, nos contó con todo lujo de detalles cómo ante la negativa de la familia a seguir escolarizando a una niña gitana, ella iba a darle clase sentada en un poyo a la entrada de la casa (10EDM). En toda la entrevista, esta maestra no hizo uso de cláusula de salvaguardia alguna, seguramente porque el contenido de su relato la habría hecho redundante.

En el fondo, toda identidad es una representación de cómo uno se ve a sí mismo en función de lo que los demás esperan ver o, mejor dicho, en función de lo que uno cree que los demás esperan ver. Pero también de cómo los otros son vistos. La identidad señala (representa), pues, una posición dentro de un sistema más amplio de representaciones que se estructura sobre todo en un espectro de diferencias. Por eso se ha dicho $-\mathrm{y}$ así hemos querido fundamentarlo en la primera sección-que la identidad se forja en la señalización [marking] de la diferencia (Woodward, 1997: 28).

En coherencia con este esquema, la representación de la identidad de rol exhibida por los docentes en el marco del proceso de producción de su identidad profesional e incluso personal debe ser puesta en relación con un sistema más amplio de representación de la diferencia que estructura el universo de posibilidades de la relación educativa interétnica en un sistema de posiciones diferenciadas. Este sistema es el que aparece resumido en el cuadro 2.

El cuadro pretende reflejar, en primer lugar, cómo ese sistema de señalización de la diferencia étnica que aparece en el discurso del profesorado constituye un todo jerarquizado. La limitación de nuestros datos no nos permite afirmar categóricamente que el proceso de representación y producción de la diferencia haya de ser siempre necesariamente jerárquico, pero lo cierto es que en el caso concreto aquí estudiado sí lo es. Desde luego, existen posiciones que mantienen esta jerarquización como una constante universal. Dumont (1983: 260), por ejemplo, afirma que «el reconocimiento del otro [...] no puede ser sino jerárquico» ${ }^{12}$. En coherencia con la sociología del conocimiento apuntada en la primera sección, podría explicarse esta constante por una necesidad epistemológica del tipo señalado por Schutz en su teoría de las diferentes capas de significatividad que estructuran el mundo social que es objeto de conocimiento (v. supra nota 3). Pero, para nuestro caso, seguramente es igualmente plausible referirla a la influencia de las estrategias cognitivas evaluativas en el ámbito escolar. Como hace tiempo señaló Jackson (1991: 50, 59, 63), la escuela es ante todo un recinto evaluativo, y lo que se evalúa — es decir, lo que se

12. Dicho sea de paso, Dumont extrae de esta premisa la consecuencia de que reclamar a un mismo tiempo la igualdad y el reconocimiento de la diferencia es un imposible. 
Cuadro 2. Sistema de representación de la diferencia étnica en el discurso del profesorado.

\begin{tabular}{|c|c|c|c|c|}
\hline Nivel & $\begin{array}{l}\text { Distancia } \\
\text { alumno } \\
\text { modelo }\end{array}$ & $\begin{array}{l}\text { Expectativa } \\
\text { rendimiento }\end{array}$ & $\begin{array}{l}\text { Principales } \\
\text { casos de } \\
\text { atribución }\end{array}$ & $\begin{array}{l}\text { Marcadores } \\
\text { discursivos }\end{array}$ \\
\hline 1 & Poca & Moderada & $\begin{array}{l}\text { Asiáticos } \\
\text { Dominicanos } \\
\text { Bosnios }\end{array}$ & $\begin{array}{l}\text { «Muy buenos» (6ETM) } \\
\text { «Muy trabajables» (17EAM) } \\
\text { «Firmaría por tener una clase } \\
\text { de chinos» (6ETM) } \\
\text { «Esos dan lecciones» (76EEJM) }\end{array}$ \\
\hline 2 & Bastante & Baja & $\begin{array}{l}\text { Magrebíes } \\
\text { Portugueses } \\
\text { Gitanos (piso) }\end{array}$ & $\begin{array}{l}\text { «Linces» (36EAM) } \\
\text { «Pero limpios» (7EETM) } \\
\text { «Gitanos de la jet» (7EPM) } \\
\text { «De mezcla» (7EPM) }\end{array}$ \\
\hline 3 & Mucha & Escasa & Gitanos (chabola) & $\begin{array}{l}\text { «No hay hada que hacer» } \\
\text { (45GDPM) } \\
\text { "Los del moco colgando» } \\
\text { (45GDPM) } \\
\text { «Se automarginan» (21ETM) } \\
\text { «Sucios» (7ETM) } \\
\text { [referido a su religión] «esa es } \\
\text { otra pobreza» (5EDM) } \\
\text { «Niños de una vez... viven en su } \\
\text { mundo» (35EPAM) } \\
\text { "Ya puedes seguir esperando, } \\
\text { que no van a cambiar» } \\
\text { (45GDPM) }\end{array}$ \\
\hline
\end{tabular}

compara y se juzga - no es solamente el logro académico. Existen, de hecho, investigaciones de las relaciones étnicas en la escuela que estudian procesos de jerarquización similares (Rist, 1970; Durand y Durand, 1988).

El eje que articula la representación jerarquizada de las diferencias étnicas del alumnado puede establecerse a lo largo de un continuo que va desde una menor hacia una mayor distancia respecto a lo que podríamos llamar la «imagen del alumno modélico» ${ }^{13}$. Esta imagen vendría a ser el corolario ideológico de la imagen del profesor ideal que hemos visto protegida discursivamente por las cláusulas de salvaguardia anteriormente comentadas. Como proyección de esa imagen del super-ego profesoral aparece la figura del lejano próximo, del alumno cercano que responde aunque sea culturalmente distante, del alumno que aprende su oficio y que se caracteriza sobre todo por su interés,

13. Aunque la noción del «alumno modélico» es fácil de comprender intuitivamente, puede verse un análisis de su construcción en Perrenoud (1990). La importancia de los componentes comportamentales y disciplinarios en su caracterización debe ser puesta en relación con los intereses concretos de la práctica docente en las tareas de gestión del aula (lo que el propio Jackson llamaba el "pensamiento educativo concreto»). 
por su sumisión, por su comportamiento no problemático y, en definitiva, por su elevado grado de correspondencia con los atributos de rol que se esperan de quienes siguen fielmente el paso de la institución escolar y su cultura organizativa $^{14}$. Quizá no sea exagerado afirmar que la percepción de la amenaza de la paz en el centro, que aumenta a medida que lo hace la distancia del alumnado respecto al modelo, está estrechamente relacionada con la percepción de la amenaza del orden social con que se produce la estereotipia de los grupos étnicos más distantes culturalmente, en ocasiones, pero más próximos en la realidad cotidiana (los próximos lejanos ${ }^{15}$. La dirección del sistema de representación sería, en este sentido, la misma que en la estereotipia del lenguaje cotidiano se establece entre las expresiones «trabajar como chinos» $\mathrm{y}$ «vivir como gitanos».

Se ha podido constatar también cómo las variables utilizadas para explicar las razones del éxito o fracaso académico fluctúan a lo largo del eje jerárquico en la misma dirección en que se sitúan los diferentes niveles de jerarquización con arreglo a la distancia percibida respecto al alumno ideal. Así, la percepción claramente complaciente que se tiene del alumnado asiático suele hacer referencia a su capacidad de esfuerzo, a su motivación y, sobre todo, a su disciplina. Estos mismos descriptores se han encontrado para el caso de alumnado procedente de los países de Europa del Este. Estos rasgos pueden llegar a potenciarse comparativamente para señalizar una diferencia étnica no conflictiva. Así ocurrió en el caso de una profesora que decía: "puestos a pedir, dame una clase de chinos» (6EETM) o en el de otra que describía la aparición de éstos en el aula «como si le hubiera tocado la lotería» $(6 E E P A M){ }^{16}$. Su bajo rendimiento académico, cuando se da, suele atribuirse normalmente a un pobre conocimiento de la lengua de acogida, se considera fácilmente subsanable e incluso se ve en ello frecuentemente un reto personal («esos bosnios sí que nos enseñaron a nosotros... lo que nos costó y lo bonito que fue», 76EEJEM).

El segundo nivel de jerarquización se presenta como el más híbrido, pues registra casos más ambiguos. El éxito académico, cuando se da, suele atribuirse a rasgos que una profesora definía como "una inteligencia especial». "Son listos — decía - y aprenden rápido, pero sólo lo que les interesa» (53GDPM). Estas caracterizaciones sintonizan con otras encontradas, por ejemplo, en el discurso de una asistenta social que describió a los «pequeñajos» marroquíes como «linces», porque — explica— «aunque no vayan bien en el cole son capaces de explicar las cosas a sus padres, los impresos, el papeleo, y todo eso»

14. O de quienes, al menos, no hacen ruido si pierden el paso o se tropiezan. Recordemos en este punto la observación de Jackson (1991: 67): "aprender a desenvolverse en la escuela supone, en parte, aprender a falsificar nuestra conducta».

15. Puede verse Calvo Buezas (1990) para un ejemplo de cómo en una escala de distancia social el rechazo a gitanos y magrebíes en el ámbito escolar es mucho mayor que a otros grupos de forma no muy distinta a como ocurre en la realidad extraescolar.

16. En Wong (1980) puede encontrarse un estudio de la igualmente positiva percepción que del alumnado de origen asiático tiene el profesorado norteamericano. 
(36EEAM). Es esa misma inteligencia la que les lleva a ser percibidos como artífices de procedimientos de aprendizaje y sujetos de conductas poco ortodoxas, que a veces pueden traducirse en engaños. Los comentarios sobre su moderado absentismo y su falta de trabajo escolar doméstico suelen ser terreno abonado para las referencias a este tipo de inteligencia. $\mathrm{Su}$, por lo general, rápido aprendizaje de la lengua hace que ésta no sea un motivo de bajo rendimiento. Cuando éste se da, suele atribuirse a la falta de una vida familiar estable, normalmente por motivos de trabajo temporal, que obliga a traslados ocasionales o bien a tener que ayudar en dicho trabajo. Son, por así decirlo, alumnos a medio camino entre la integración y la exclusión que —al menos en el contexto estudiado- viven en la tenue frontera de una etnicidad débil y que en algunos casos siguen experimentando una fuerte discontinuidad entre su vida familiar y/o su cultura de origen y la cultura escolar. Esto, a veces, se ha llegado a percibir simplemente tras una larga ausencia como, por ejemplo, la de las vacaciones. Un profesor (44EEPM) decía que «vuelven locos, trastornados... como si no hubiéramos hecho nada durante semanas... y hay que volver a comenzar a tranquilizarlos, con las normas y todo eso".

Es de señalar también que el recurso a descripciones físicas (limpieza, aspecto aseado, ropas, etc.) tiende a ser más frecuente cuanto mayor es la distancia social percibida por el grupo dominante. Apenas aparecen en las referencias a los alumnos del primer nivel de jerarquización; son más frecuentes en el segundo nivel, sobre todo para subrayar parecidos en los casos de éxito ("y es que..., de verdad, ni parecía gitano, aseado y todo»; «sí, su padre es senegalés, negro, negro... pero alto y guapetón donde los haya... y muy liberal» (9EEDM); y proliferan en las referencias a los alumnos del tercer nivel, donde la señalización física a menudo se refuerza con referencia al olor.

Como ya se ha podido entrever, el tercer nivel de jerarquización suele aplicarse al alumnado claramente diferenciado por todos aquellos rasgos que caracterizarían a la etnicidad fuerte que puede exhibir una verdadera minoría étnica ${ }^{17}$. Son percibidos, casi huelga decirlo, como los firmes candidatos a la exclusión social vía un fracaso escolar que, más que causarla, la reproduce. Es en referencia a este tipo de alumnado en donde más puede verse el efecto de una doble discriminación (Fernández Enguita, 1996) a través de una señalización discursiva de carácter peyorativo: a la distancia percibida por la no pertenencia al endogrupo se suma la producida por los rasgos conductuales que se consideran desviados (no meramente diferentes). En consecuencia, su representación responde a un nivel de jerarquización que podríamos definir como propio de un alumnado paria o, simplemente, infraalumnado. Se ha

17. En otro momento de nuestro estudio planteamos la conveniencia de distinguir entre las minorías étnicas propiamente dichas y los casos de simples colonias o los casos aislados. Distinguimos, en la base de cada uno de ellos, tres procesos distintos (dispersión, agregación, sedimentación) que intentamos aplicar a la población estudiada en nuestro ámbito para tener una visión más ajustada de su heterogeneidad. Seguimos en este punto las recomendaciones de Giménez (1996). 
observado que la distancia social percibida está, en este caso, muchas veces marcada por el olor, una señal diferenciadora más biologicista que culturalista y que ya Park (1964: 240) destacó como la más íntimamente relacionada con la antipatía racial ${ }^{18}$.

Es cuando el discurso se orienta hacia ellos cuando más tienden a proliferar las cláusulas de salvaguardia y cuando normalmente tienen lugar dicotomías marcadamente polarizadas a través, por ejemplo, de las descripciones del aspecto físico a las que anteriormente hicimos referencia. Es éste, pues, un tipo de elección léxica que tiende a subrayar el distanciamiento. Unas y otras parecen responder a una estrategia de proteger el autoconcepto profesional y, al mismo tiempo, favorecer una atribución del fracaso en su integración a elementos extraescolares como la familia, su idiosincrasia o, simplemente, en una archirrepetida expresión, a su «forma de ser».

Nos encontramos, en definitiva, con que la producción de la relación étnica en el discurso de los profesores y profesoras con experiencia directa en el trato con alumnado de procedencia distinta a la étnicamente mayoritaria no difiere esencialmente de la lógica de la etnicidad jerarquizada que se ha podido apreciar en otros sujetos y en otros contextos ${ }^{19}$. Quizá por el apreciable grado de motivación y dedicación de este sujeto productor, su sistema de representación de la diferencia étnica está más vinculado a mecanismos de racionalización y expresiones discursivas que intentan afianzar una identidad profesional a salvo de cualquier sospecha de comportamiento racista o simplemente discriminatorio. Parece claro que dicha identidad queda reforzada en los casos - normalmente del primer nivel — en que se consigue «sacar a flote» al alumno. Cuando no se consigue - como ocurre normalmente con el alumnado del tercer nivel—, la identidad profesional, que no puede verse reforzada como en el caso anterior, tiende a ser discursivamente protegida con la formulación de cláusulas de salvaguardia y la atribución del fracaso a factores socioculturales extraescolares. Dicho de otra forma, mientras que en los casos de mayor distancia social percibida la diferencia es representada como una amenaza que obliga a un rígido gesto discursivo de autoafirmación identitaria, en los se percibe una cercanía, la diferencia deja de ser vista como un foco de inseguridad y, en consecuencia, la identidad profesional que se pone en juego en la relación queda reforzada por la propia interacción.

$\mathrm{Si}$ — como ha señalado Fernández Enguita (1996) siguiendo a Jacksonla escuela es el escenario en el que uno aprende a sustituir su autoestima por la evaluación que los demás hacen de él, y si algo de razón lleva la teoría del eti-

18. Debido a su sentido como reacción orgánica, el olor puede entenderse como un prejuicio que alberga el menor grado posible de racionalización. Sin embargo, puede incorporarse a ésta, como ocurre cuando una profesora (60EEOM) lo utilizó para diferenciar a los compañeros motivados en ayudar a los gitanos de los que «abren las ventanas cuando entran en una clase con gitanos».

19. Lo primero ha sido señalado, por ejemplo, por el Colectivo IOÉ (1994) y lo segundo, por Samper (1996) y Durand y Durand (1988). 
quetaje, es muy probable que las representaciones de la diferencia étnica observadas en el discurso del profesorado puedan influir en rendimientos e identificaciones diferenciales por parte del alumnado. De hecho, como tratamos en otra parte de la investigación, hemos encontrado una fuerte sensación de apoyo en alumnos y alumnas de origen asiático que contrastan con las creencias fatalistas y el derrotismo manifestadas por algunos alumnos y padres gitanos o portugueses. Esta identificación diferencial puede estar en la base de los diferentes compromisos desde los que puede abordarse la relación educativa, compromisos que podrían situarse comparativamente en una escala que fuera de la asimilación a la resistencia cultural. Con ello se reforzaría una oferta disyuntiva que puede minar el proyecto de una educación intercultural: integrarse en la cultura dominante transformándose en malas copias o mantener la especificidad al precio de la desvalorización (Juliano, 1994). A la disyuntiva subyace la premisa cognitiva que Elias (1997) considera como típica del discurso de «los establecidos»: identificar la superioridad con el mérito y ambos con su autoimagen.

En cualquier caso, sí parece mostrado que —al menos en el contexto educativo y para el caso del profesorado, aunque seguramente no sólo en él ni sólo para este caso- la relación interétnica pone en marcha en los sujetos implicados unos mecanismos discursivos de señalización de la identidad que expresan su conciencia de la diferencia étnica y que siempre parecen tender a estructurarse de forma dicotómica (nosotros/otros) y jerarquizada (diferentes tipos de otros). Aunque es necesario profundizar en una teoría del racismo elemental y extender el espectro de sujetos y situaciones a estudiar, parece que el análisis de la señalización discursiva de la diferencia ofrece una buena perspectiva para conocer mejor cómo (y no sólo qué) piensan las personas acerca de las que no pertenecen a su grupo étnico; esto es, para entender cómo funciona la conciencia de la diferencia y cómo se construyen las actitudes étnicas.

\section{Bibliografía}

BARTH, F. (ed.) (1976). Los grupos étnicos y sus fronteras. México: Fondo de Cultura Económica.

Bonilla-Silva, E.; Forman, T.A. (2000). “"I'm not racist but...” Mapping White college students racial ideology in the USA». Discourse \& society, 11(1), p. 50-86.

Calvo Buezas, T. (1990). El racismo que viene. Otros pueblos y culturas vistos por los profesores y alumnos. Madrid: Tecnos.

ClaY, J.; Cole, M. (1992). «Euroracism, citizenship and democracy: the role of teacher education». Studies in sociology of education, 2(1), p. 75-88.

Colectivo IOÉ (1994). «La inmigración extranjera en España». En CONTRERAs, J. (comp.). Los retos de la inmigración: racismo y pluriculturalidad. Madrid: Talasa.

- (1999). «La interculturalidad va al cole?». Ofrim, suplementos, noviembre-diciembre, p. 47-64.

Dumont, L. (1983). Essais sur l'individualisme. París: Seuil.

Durand, B.; DuRAND, J.Cl. (1988). «Hiérarchisation des élèves asiatiques, maghrébiens et tsiganes à travers la représentation des maîtres». Cahiers de l'ERISI, 1, p. 25-30. 
Elias, N. (1997). Logiques d'exclusion. París: Fayard.

FAIRCLUGH, N. (1995). Critical discourse analysis. Londres: Longman.

FERNÁNDEZ ENGUITA, M. (1996). Escuela y etnicidad: el caso del pueblo gitano. Granada: CIDE-Laboratorio de estudios interculturales.

GIMÉNEZ, C. (1996). «La formación de nuevas minorías étnicas a partir de la inmigración». En MARTín Rojo, L. y otros (coords.). Hablar y dejar hablar. (Sobre racismo y xenofobia). Cantoblanco, Madrid: Ediciones de la Universidad Autónoma de Madrid, p. 177-200.

GofFMAN, E. (1987). La presentación de la persona en la vida cotidiana. Buenos Aires: Amorrortu.

GoOD, T.L.; BropHY, J.E. (1991). Looking in classrooms. Nueva York: Harper-Collins. HaLl, S. (1997). "The work of representation». En Hall, S. (ed.). Representation. Cultural representations and signifying practices. Londres: Sage.

IzQUIERDO, A. (1996). «Las encuestas contra la inmigración». En MARTín RojO, L. y otros (coords.). Hablar y dejar hablar. (Sobre racismo y xenofobia). Cantoblanco, Madrid: Ediciones de la Universidad Autónoma de Madrid, p. 165-177.

JACKSON, Ph. (1991). La vida en las aulas. Madrid: Morata.

JENKINS, R. (1986). «Social antropological models of inter-ethnic relations». En REX, J.; Mason, D. (1986). Theories of race and ethnic relations. Cambridge: Cambridge University Press, p. 170-186.

JORDAN, J. (1988). "An analysis of the problem of disppearing black educators». The Elementary School Journal, 88 (5), p. 503-513.

Juliano, D. (1994). «La construcción de la diferencia: los latinoamericanos». Papers, 43, p. 23-32.

LiÉGOIS, J.P. (1998). Minoría y escolaridad: el caso del pueblo gitano. Madrid: Centre de Recherces Tsiganes / Presencia gitana.

MURILlO, F.J. y otros (1995). «La investigación española en educación intercultural». Revista de educación, 307, p. 199-216.

PARK, R. (1950). Race and culture. Nueva York: Free Press.

Perrenoud, J. (1990). La construcción del éxito y del fracaso escolar. Madrid: Morata. PUIG, J.M. (1994). «Diversidad étnico-cultural: una prueba para la democracia y la educación». En Santos Rego, M.A. (ed.). Teoría y práctica de la educación intercultural. Santiago de Compostela: Servicio de Publicaciones de la Universidad de Santiago.

ReX, J.; MASON, D. (1986). Theories of race and ethnic relations. Cambridge: Cambridge University Press.

Riggins, S.H. (1997). «The rethoric of othering». En RigGins (ed.). The language and politics of exclusion. Others in discourse. Londres: Sage, p. 1-30.

RisT, R. (1986). "Sobre la comprensión del proceso de escolarización. Aportaciones a la teoría del etiquetaje». Educación y sociedad, 8, p. 180-191.

- (1970). «Social class and teacher expectations: the self-fulfilling prophecy in ghetto education". Harvard Educational Review, 40, p. 441-451.

Rosenthal, R.; Jacobson, L.F. (1980). Pigmalión en la escuela. Madrid: Morata. SAMPER, Ll. (1996). "Etnicidad y curriculum oculto: la construcción social del "otro" por los futuros educadores». En SolÉ, C. (ed.). Racismo, etnicidad y educación intercultural. Lleida: Edicions Universitat de Lleida, p. 63-100.

SANTOS REgO, M.A. (1999). «El progreso de la democracia: interculturalismo y fortalecimiento de la sociedad civil». En SANTOS REGO, M.A.; TOURIÑÁN, J.M. (eds.). Interculturalidad y educación para el desarrollo. Santiago de Compostela: Xunta de Galicia, Consellería de Cultura. 
SCHÜTZ, A. (1974). Ensayos de teoría sociológica. Buenos Aires: Amorrortu.

Simmel, G. (1986). Sociología. Madrid: Alianza.

SMiTH, D.; TOMLINSON, S. (1989). The school effect: a study of multiracial comprenhensives. Londres: Policy Studies Institute.

TAguiefF, P-A. (1980). La force du prejugé. París: Fayard.

Terrén, E. (1996). «El redescubrimiento de la etnicidad». En Pensar lo humano. II Congreso nacional de antropología filosófica. Madrid: Iberoamericana, p. 337-345.

VAN DIJK, T.A. (1987). Communicating racism. Londres: Sage.

- (1988). «El discurso y la reproducción del racismo». Lenguaje en contexto, 1 (1/2), p. 131-180.

WaLLMANN, S. (1979). Ethnicity at work. Londres: MacMillan.

WEINREICH, P. (1986). «The operationalisation of identity theory in racial and ethnic relations». En REX, J.; MASON, D. (1986). Theories of race and ethnic relations. Cambridge: Cambridge University Press, p. 299-320.

Wievioka, M. (1992). El espacio del racismo. Barcelona: Paidós.

WONG, M.G. (1980). "Model students? Teacher's perceptions and expectations of their Asian and white students». Sociology of education, 53, p. 236-246.

WoOdWARD, K. (ed.) (1997). Identity and diffrence. Londres: Sage. 